\title{
THE NEGATIVE IMPACT OF TOURISM IN THE AREA OF THE BÂRGĂU MOUNTAINS ONTO THE LOCAL ENVIRONMENT Lia-Maria CIOANCĂ
}

\author{
“Babeș-Bolyai”" University, Cluj-Napoca, The University Extension of Bistriţa
}

\begin{abstract}
Tourism as any other human activity causes a negative impact on the environment when the general rules of behaviour and management are not fully respected. Actually the growing development of tourism and the increasing number of tourists in the area, have had a negative but prominent effect on the local environment as well.
\end{abstract}

Keywords: impact, tourist planning, preservation, long-term development

\section{General considerations}

Tourism is a way of relaxing, people want to escape from everyday worries. In this respect, people will appeal to the geographical environment qualities to satisfy their recreational or curative needs. This way attracting huge masses of people, with their temporary migration from one region to another, tourism inevitably has an obvious impact onto the environment. Although man takes on only its aesthetic qualities, the effects of practising tourism, come up alone or in accumulation, eventually turning into negative and disruptive factors (Barta, 2011).

Topographically, the forms of tourist human impact directly concern the way and the location of the accommodation sites, the type of accessibility needed and the action of tourist objective and space planning. Accommodation and leisure units, by nature, involve constructions which mould the corresponding relief nearby, whether it comes of terrain levelling or consolidating it. The repercussions of the most obvious elements of tourist infrastructure are most of the time located within the very tourist area, dividing and most often shattering it.
Tourist service units may affect the landscape either through their architecture or through misadaptation to the specific place. The access way building has a much more prominent effect than the action of positioning the service units as, the former affects, by far, larger areas. Thus, the access ways may both lead to the destruction of certain relief elements and, moreover represent a risk factor within the crossed perimeter due to oscillations produced.

Nature pollution increases gradually due to the automotive tourism whose harmful effect is impairing air quality, the destruction of meadows, shrubs and vegetation. Another way of negatively affecting the environment, consists in making touristically unscientific and irrational investments in the area, namely: oversized-resorts in terms of reception and treatment capacity and not a proper compliance with the general principles of natural resource exploitation. That is why the previously analyzed aspects suggest once more that, besides other social and economic activities, tourism still constitutes an important source of pollution which automatically involves its inherent ecological development. 


\section{The impact of the week-end and leisure time tourism onto the environment}

The environmental quality is generally affected by two broad categories of key factors, objective and subjective ones caused by human activities. Among the numerous activities through which one can damage the environment up to its destruction, the tourist activities emerge irrationally and uncontrollably deployed in the area.

The destructive actions of these tourist activities practised by man when it refers to tourism week-end related to a certain extent with the recreational tourism, get materialised mainly through the misuse of the local environment, that is woods, forests, clearings etc., for recreation and leisure time purposes, continually enhanced by an improper interference of the humans on the landscape, namely the undiscovered and the implicit existing natural resources. In many Romanian cities, the forests from the outskirts seem to be more or less arranged for tourist purposes. All this happens especially during the weekend, when they attract a significant number of tourists, thus deploying an uncontrollable, endless tourist flow. Most of the damage caused by humans onto the environment is irreversible (Barta, 2011).

Unfortunately all this starts from kind of an ignorance of everything related to green space, fauna, vegetation which, because of tourist activities deployed, waste of all kinds, phonic pollution, are endangered.
Most tourists avoid the specially arranged pathways of access taking the back roads, shortcuts and the unmarked ones, eventually stopping in picturesque clearings not necessarily designed for camping, installing tents or having barbecues, which unfortunately lead to their disappearance, to the destruction of meadows, small trees, bushes and generally the whole vegetation. Similarly, within these meadows, the damage caused is huge and irreversible leading to the destruction of vegetation, tree splitting up or their cutting down for lighting fires in inappropriate places, or worse causing damage or destructing plants and flowers of enormous relevance, yet leading somehow to their extinction, for instance, the uncontrolled human actions regarding certain species of plants, legally protected and on the verge of extinction. As concerns the installation of tents and parking for picnics in totally inappropriate places, people seem not to realize the seriousness of their actions in terms of soil compaction and implicitly the residual stuff left at random by tourists in camping places.

However, soil quality appears to be also affected, their pollution being a result of some unhygienic habits or improper use regarding waste disposal at random and edible food debris resulting from the activity of humans who, would rather throw them all round camping areas and rivers than in specially arranged spaces for storing them, or even special bags brought by them from home (Barta, 2011). 


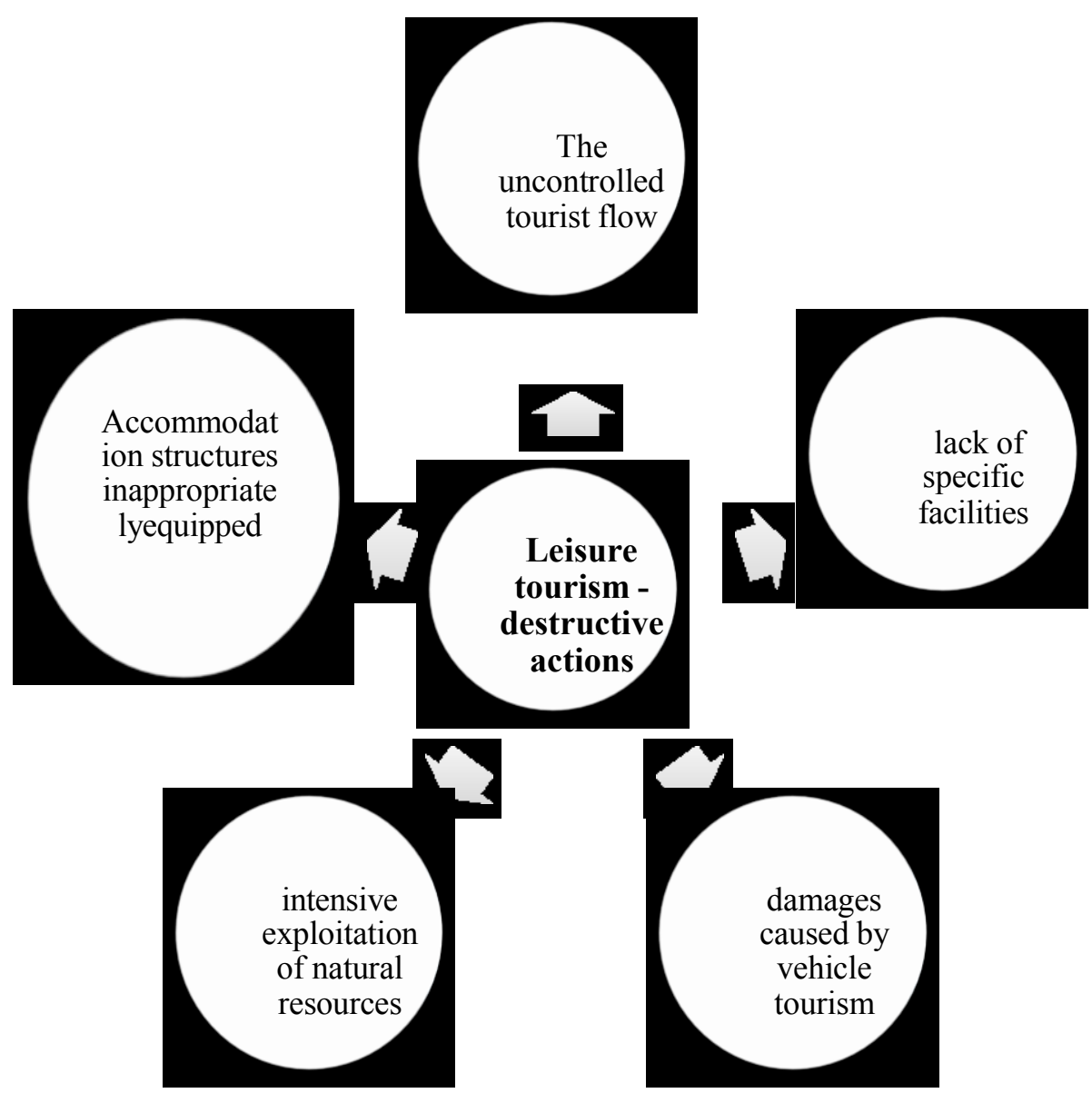

Figure 1: Most often destructive actions of leisure tourism (Barta, 2011)

Given the relatively quick development of these leisure time tourist activities, the phenomenon of negative impact regularly enhances. All this may be not only the cause of the expansion of structures and tourist services, instead of using to full capacity the existing facilities, but also the increasingly rapid urbanization of cities, this increase in its turn, being influenced by the extensive flow of tourists, fact leading to the supersaturation of the actual tourist infrastructures and to a certain diversification of pollution forms. In this respect, the question of a well-run and managed development of tourism arises, especially in tourist areas with the status of natural reservations and national parks. In other words, the tourist activities undertaken in a preserved area must be according to ecologically load capacity and the specific features of th existing ecosystems. The appropriate and cautious restructure and the effective tourist re-evaluation on one hand, and the efficient management, on the other, must be an essential pillar when it comes of preseving such resources.

In conclusion, the recreational tourism, like the other types of tourism as well, it is beneficial and necessary both for tourists and a country's economy and even for the environment, if wisely practised, respected and treated with common sense towards it; Moreover, if today nature seems to lose, in the future we will certainly be the only ones to fail. 


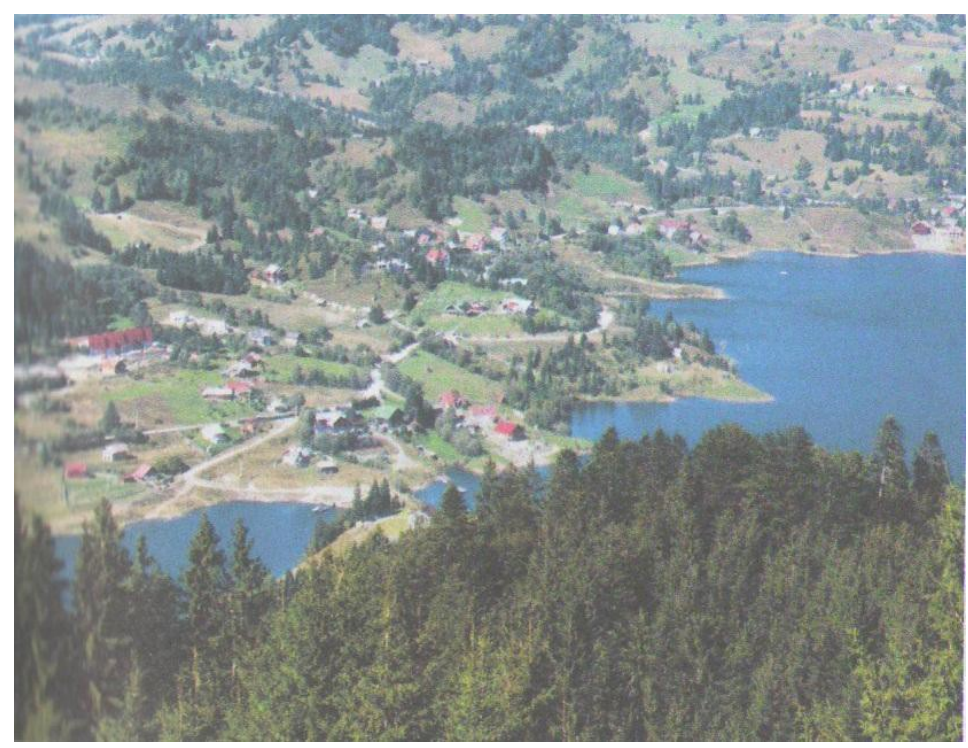

Figure 2: Impact onto the environment tourist facilities in the Colibita area

\section{The impact of tourism onto the environment in the mountain areas}

Tourism has a positive impact onto the environment since it is one of the most important industries which, actually records a continuous development. Thus, the areas that possess extraordinary natural resources, attract more and more visitors, even more if they offer the opportunity to get to know the customs and traditions. When tourism and the environment coexist harmoniously, the environment is the only one which benefits from tourism. There are many examples of the kind, most of them belonging to one type or another, namely preservation and restoration of the environment which most often go altogether. One conclusive example would be the tourist potential of the Bârgău Mountains offered both by its natural resources and the various local human resources.

Tourism, like any other human activity causes a negative impact onto the environment when the general rules of management and behaviour are not fully respected. The relatively quick development of the tourism sector and the increasing number of tourists, make the impact onto the environment increase faster and faster. In addition to high energy and water consumption, the tourists` behaviour may constantly imperil the landscape and endanger a great deal of species of plants, animals and fish. Waste, if dumped at random, then the residual water drained without any treatment, the fire destruction of certain green areas, are just a few examples of the negative impact of tourism onto the environment.

The mountain tourism from the before analyzed unit, has a high potential due to the diversity and complexity of the picturesque mountain landscapes, karst and glacial area landforms which are more than suitable for winter sports. For these tourist objectives of great value to become touristically and economically reliable, a whole package of measures are more than compulsory. The possibilities of practising tourism may be enhanced by improving the quality of services and facilities necessary to provide a diversified range of recreational activities.

\section{The impact of the hotel activities onto the environment}

The excessively developed tourism or the poorly planned one, affect the natural environment of destination. In many areas, mentality and commercial exploitation of tourism allowed the appearance of some 
inaesthetic buildings (hotels, motels and hostels) which do not match the architecture or the environment nearby. Obviously they have been built not only to attract tourists but also for immediate winnings, without even thinking at their integration into the landscape. The effects become sometimes dramatic, especially when filled with trash and debris of the so-called "development", due to tourists whose traces can be seen on large areas with fertile soils, on water banks (rivers, lakes, seas), or urban properties or in their vicinity.

Each hotel unit must create their own proactive protection policies of the environment, whether they are part of a famous company or they are a family business. The corporate policies, namely that ones of the hotel chains, either national or international, can not disregard the location area of the hotel unit, its climate,its particular operating conditions and the legal constraints related to the environmental policies of the respective country. If these official policies do not exist, the operators of these corporations have a moral duty to insert them. However, each hotel unit has its own identity, its characteristics and, therefore, it is necessary for the information on the environment to be creatively used and effectively applied .

\subsection{Effluents and gas emissions}

This section refers to the emission (onto the soil, in the water or air) of liquids or gas substances which may affect human health and generally the whole environment.

The hotel units eliminate large amounts of liquid waste, generated from the technological processes of cooking production areas, common toilets, bathrooms, laundries and dry cleaners.

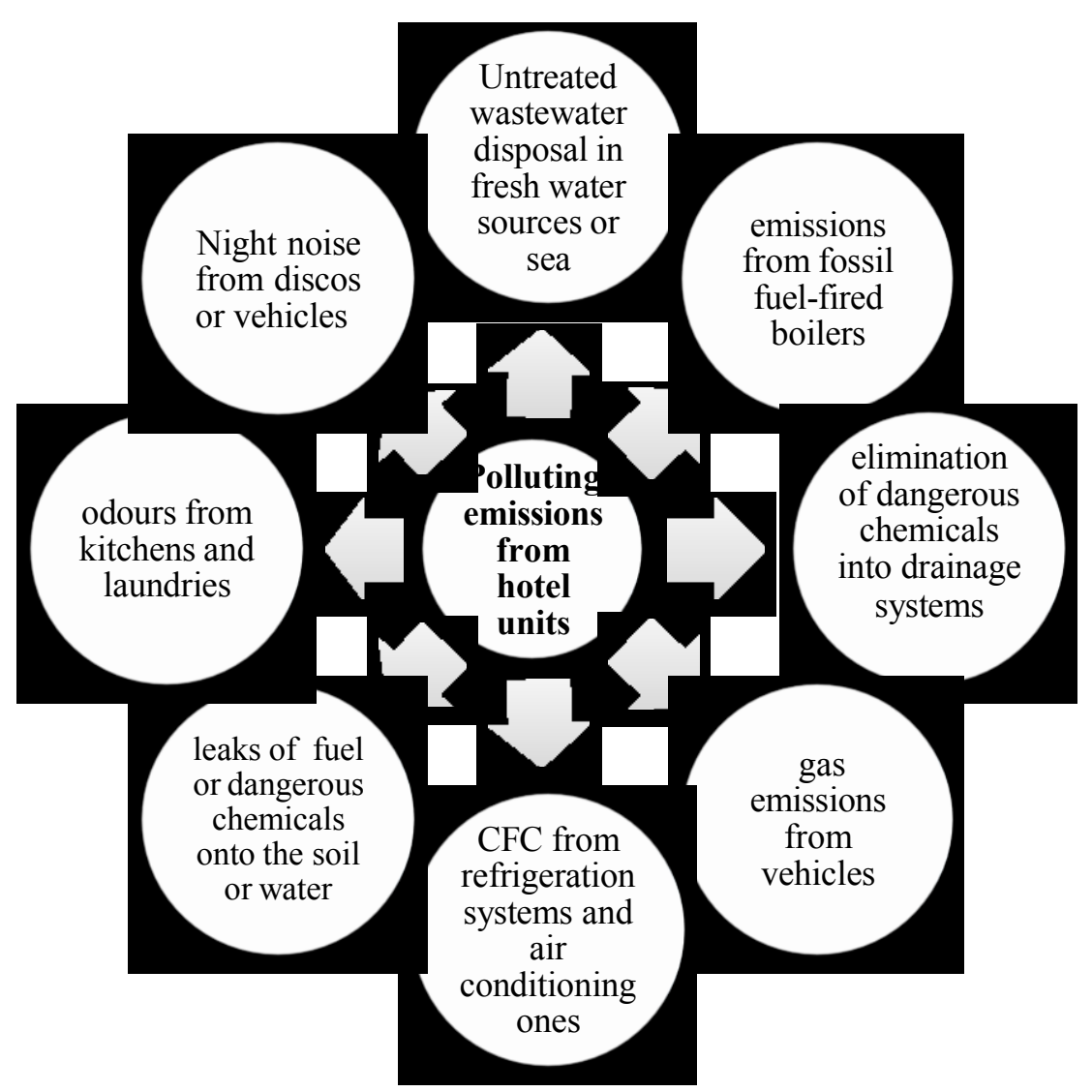

Figure 3: Polluting emissions from hotel units (Barta, 2011) 
The impairment of air quality is extremely damaging for the tourist traffic. For those who lead and provide top class activities,there is the possibility of implementing a set of concepts, choice courtesy - that is familiarizing smoking and nonsmoking customers in the hospitality industry, concepts that offer complex solutions both for the environmentally friendly operations and for the ventilation or air conditioning systems.

In the hereby research area, there are five hotel units, which are: The Hebe Hotel and the Spa, the Someş Hotel from SângeorzBăi, the Ineu Hotel from Rodna, the Heniu Hotel from Prundu Bârgăului, the Dracula's Castle Hotel from Piatra Fântânele, which works more or less succesfully.

Although the Bârgău Mountains have a unique natural landscape beauty and natural resources of great interest (mineral waters, salt waters, pits), these resources are not fully exploited to their true value by tourist structures in the area.

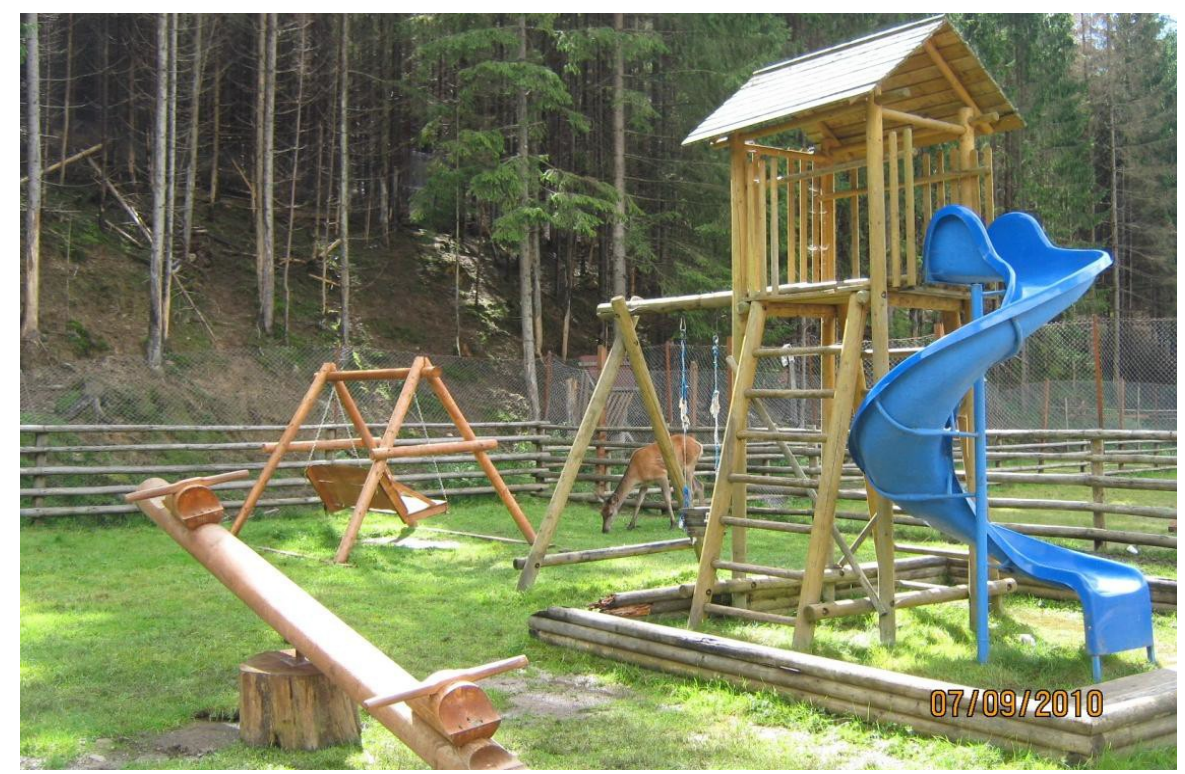

Figure 4: Keeping animals in captivity in inappropriately establised places and the danger of getting sick - the Poiana Zanelor(the Fairies 'Clearing) from the Valea Mare

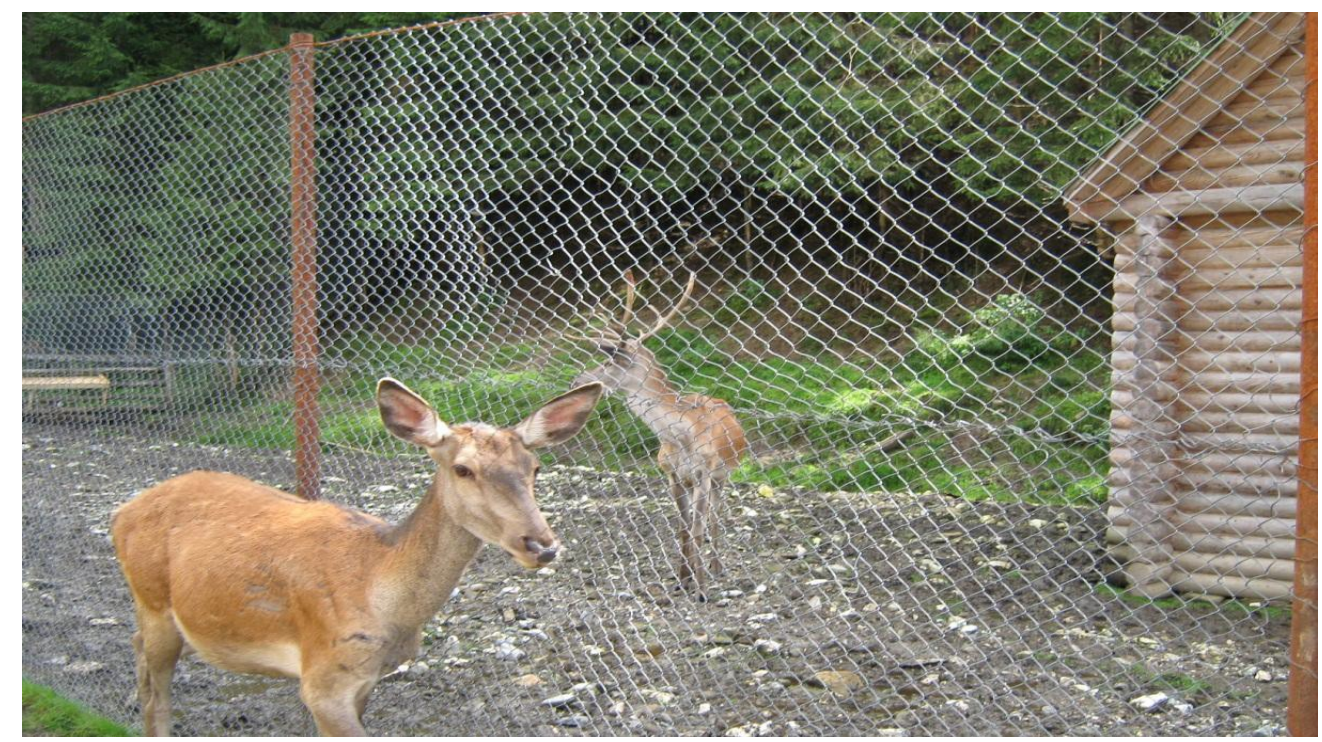

Figure 5: Animals in captivity at the Valea Mare 
Waste resulted from the tourist activities Among many environmental problems which seem to menace our planet, a major issue is, undoubtedly, waste. The terms of consumption society, waste avalanche and waste crisis are just a few examples illustrating the problems created by waste, which our ministry of environment goes on striving to cope with. As consumers, we are all responsible for these issues and in the future, each of us will have to do their best to spare the limited resources this way, reducing waste amount. It is undeniable that, nowadays we produce more waste containing recyclable materials and problematic substances that are rightfully considered as residues.

Although the effects onto the vegetation and fauna are theoretically time confined as regards the duration of residual exploitation, the ecological reconstruction performed after carrying out the technological tasks area, will not be able to restore the initial biological balance, the biosystem evolution being irreversibly altered. It is strikingly obvious that this change cannot be achieved in a day's time, but it is much faster, the essential criteria being, transparency and reliability, motivation, systematic action, good infrastructure and, at least but not at last, the reduction of our personal comfort.

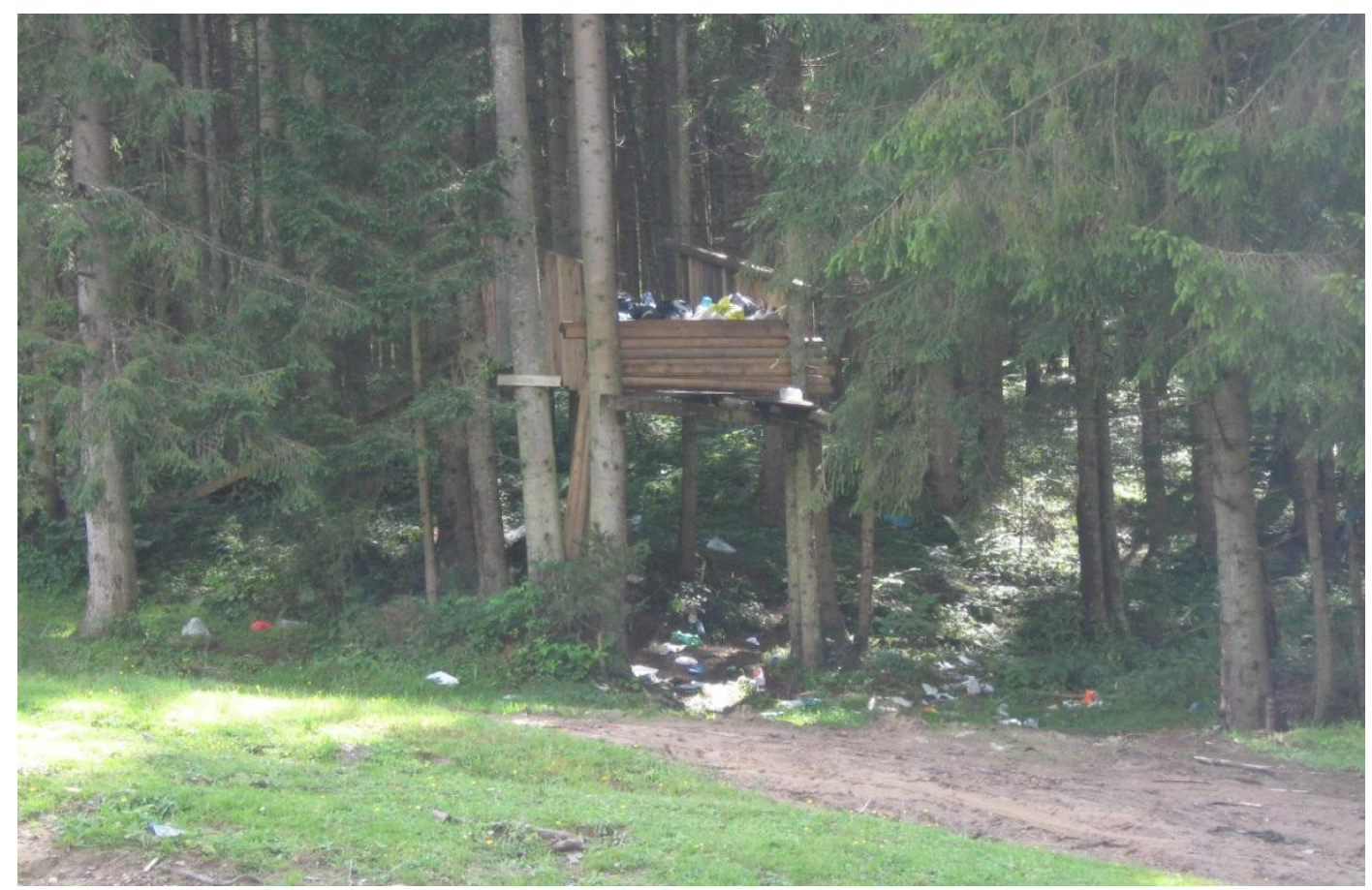

Figure 6: Improper waste disposal

All quality problems derive from the potential of the natural environment to withstand, without significant disturbances, certain forms and intensities of the human pressure. The human impact onto the environment represents any more or less direct effect of a human activity defined in a certain area, which produces a change in the direction of evolution, of quality status of the ecosystem, change which may eventually affect the human health, the environmental integrity, of the cultural heritage or the socio-economic conditions. For a long time, man had a limited influence onto the nature, today the exploitation process of the natural environments getting to a larger scale, without taking into account the perturbations caused to these environments and the difficulty of their being eliminated. In other words, if he 
does not interfere in time to stop these degrading phenomena, sometimes even more unconsciously he, nevetheless, accelerates them.

The risk analysis responds to numerous challenges, which are partly technical and partly involving issues of public acceptability. The most relevant application of the final results may be found in decision-making processes, regarding the development of certain activities and the use of substances which suppose serious human health problems and environmental quality issues.

The lack of information has led many wellintended people to persist in environmentally damaging actions, without realizing that they themselves had a negative contribution in this respect. The changes brought to the environment were often slow and very hard to perceive, although some of them apparently insignificant caused irreversible damage, such as the widespread use of pesticides, mercury pollution and the use of noxious substances such as asbestos.

All these actions whose effects are, therefore breaking the ecological balance, which may lead to health, mental peace damages or even discomfort to people or ecomony, by modifying the environmental quality factors or created through human activities, all this refers to the environmental pollution. As a matter of fact, pollution is any human action which in the end, negatively affects nature.

\subsection{Measures necessary to reduce and} eliminate the tourist risks

These actions include the adoption of emergency measures to consolidate, rehabilitate and keep the original character of the tourist objectives, so that it does not appear any risk of imminent degradation due to natural causes or frequent visits; replanning the road network and constructing new access ways, maintaining unaltered the landscape aesthetics in the region; facilitating through means adapted from one case to another, some tourist investments, so that they do not affect the integrity of objectives and their preserved areas.

Given the fact that such projects require extraordinary organizational and financial efforts, not only an overall objective assessment of the existing resources available is more than imperative but also the impact of tourism onto the natural and artificial environments as well.

In conclusion, one can state that tourism represents a space and tourist resource consuming factor, participating in the degradation and pollution of the environment and the tourist potential. This degradation is possible either through direct pressure of tourists onto the landscape, vegetation, fauna and other tourist objectives which tourism, in its turn, can partially or totally damage, or worse through the misconception of revalorizing some areas, spots and sights of great tourist interest. It is not often that one comes across visitors arrived at the destinations whose ordinary capacity reception has been, by far, exceeded. Rarely does environment escape the negative effects caused by the large number of tourists. Moreover water and air quality, the diversity of vegetation and fauna are, nevertheless, partly affected and so are landscapes, cities and monuments.

\section{Bibliography}

Barta, A. (2011), Caiet de lucrări practice, Presa Universitară Clujeană, Cluj-Napoca

Buckley, R.C. (1996), Sustainable Tourism, Issues and Management Tools, Annals of Tourism Research

Dezsi, Şt., Ciangă, N., Rotar, G. (2002), Consideraţii privind impactul turismului asupra mediului înconjurător şi riscurile induse de activităţile turistice, în Vol. I, Riscuri şi Catastrofe, Editor Victor Sorcovschi, Ed. Casa Cărţii de Ştiinţă Cluj-Napoca 
*** (2014), Raportul privind starea factorilor de mediu pe anul 2013, Ministerul Mediului şi Gospodărirea Apelor, A.P.M. Bistriţa - Năsăud.

*** ISO 14001 - Sisteme de management de mediu - Specificaţii şi ghid de utilizare.

*** ISO 14004 - Sisteme de management de mediu - Ghid privind principiile, sistemele şi tehnicile de aplicare

http://bistriteanul.ro 